\title{
Fixed point results for Suzuki Type $\Sigma$-contractions via simulation functions in modular b-metric spaces
}

\author{
Mahpeyker ÖZTÜRK ${ }^{1}$ and Abdurrahman Buyukkaya ${ }^{2}$ \\ ${ }^{1}$ Sakarya University \\ ${ }^{2}$ Karadeniz Technical University
}

November 26, 2020

\begin{abstract}
This study aims to introduce Suzuki type Econtraction mappings with simulation functions in the frame of modular b-metric spaces. Also, some coincidence and common fixed point results are obtained for four mappings using the weakly compatibility property that these results are the extensions and improvements of the existing literature. Finally, we also present two applications on graph theory and homotopy theory, which show applicability and validity of our results.
\end{abstract}

\section{Hosted file}

FixedpointresultsforSuzukiTypeSigma-ContractionsviaSimulationFunctionsinmodularb-metric spaces.pdf available at https://authorea.com/users/379151/articles/495462-fixed-point-results-forsuzuki-type-\%CF\%83-contractions-via-simulation-functions-in-modular-b-metric-spaces

\section{Hosted file}

FixedpointresultsforSuzukiTypeSigma-ContractionsviaSimulationFunctionsinmodularb-metric spaces.tex available at https://authorea.com/users/379151/articles/495462-fixed-point-results-for-

suzuki-type-\%CF\%83-contractions-via-simulation-functions-in-modular-b-metric-spaces 